\title{
USE OF CLOUD COMPUTING TOOLS IN VIRTUAL FOUNDRIES
}

\author{
Michal FRIDRICH, Ivo ŠPIČKA, Tomáš TYKVA \\ VSB - Technical University of Ostrava, Faculty of Materials Sciences and Technology, Ostrava, \\ Czech Republic, EU, michal.fridrich.st@vsb.cz, ivo.spicka@vsb.cz, tykva@bintell.cz
}

https://doi.org/10.37904/metal.2019.780

\begin{abstract}
The arrival of the fourth industrial revolution (Industry 4.0) opens the door to a completely new concept called a virtual foundry. The concept is a specific type of digital factory. A virtual foundry can be imagined as a simulation of a fully functioning company, encompassing all elements of the production process, from receipt of goods, through logistics to sales to the end customer. With the virtual foundry, it will be possible to shorten the time of the entire production process, deliver products faster to customers, reduce innovation cycle times and achieve greater energy and resource savings. High employee turnover is a serious problem for many companies, as training new employees is very expensive. The virtual foundry can also serve as an educational tool for new employees. This new concept will certainly be demanding on hardware requirements. This could solve the interconnection of the virtual foundry with cloud computing. Cloud computing can be defined as a new form of computer usage where data is processed, stored and managed on remote servers hosted on the Internet instead of a local server or personal computer. Cloud computing has become a major technology trend, and many experts assume it will change not only information technology processes but also the entire IT market. This article aims to define, on the basis of available literary and news sources, the possibilities of a virtual foundry and the benefits of linking a virtual foundry to cloud computing.
\end{abstract}

Keywords: Cloud computing, Industry 4.0, virtual foundry

\section{INTRODUCTION}

With the advent of the fourth industrial revolution, many businesses are forced to devise new ways of optimizing processes from goods receipt, through the main process of production to the delivery of products to end customers. Commonly used computing models for saving time and energy are becoming obsolete and new possibilities need to be sought to maintain competitiveness. One of the problems with foundries is often poorly processed process documentation. This problem stems from the data collection itself, which often causes the data to be unusable for further processing. Recently, some of the technology giants (such as Siemens) are trying to come up with a comprehensive data processing and visualization solution called a digital factory. The digital factory uses digital technology to model, communicate, and control manufacturing or other processes.

Term virtual foundry can be imagined as an interactive software application that visualizes all its processes. This may serve, for example, to improve the training of new employees, or to simulate the production of nonserial products. This particular article will develop the intended concept into an idea design.

The virtual foundry will have very high hardware requirements and it is, therefore, appropriate to consider in advance the use of cloud computing, the undisputed advantages of which include flexibility, performance, and affordability.

This article aims to define, on the basis of available literary and news sources, the possibilities of a virtual foundry and the benefits of linking a virtual foundry to cloud computing.

\section{BASIC PRINCIPLES OF VIRTUALIZATION IN FOUNDRIES}

This chapter describes the basic principles of digital factory focusing on the foundry industry and also opens up the topic of using cloud computing in a virtual foundry. 


\subsection{Possibilities of virtualization - digital factory}

Factory virtualization means creating a simulation of real components of a given company and its processes. These processes work just as they do in the real world, but only as their image. To make the idea easier, you can use a comparison to virtual reality, which is a very hot topic recently. It is a technology that uses sophisticated visual projection and feedback from sensors to give a person the feeling that he is really in a newly created environment. The first attempts at system virtualization date back to the 1960s [1].

Digital factory is a comprehensive approach to connecting digital models, methods and tools, such as simulation modeling and virtual reality visualization - all in the presence of constant data management. The digital factory encompasses a rich virtualized environment, featuring a range of factory activities that facilitate corporate resource sharing, information, and knowledge management, and help all process participants and factory departments simulate collaboration, product design, planning, and production [2].

The foundry industry could benefit from the concept of a digital factory in exactly the same way as automotive companies or telecommunications manufacturers. The virtual foundry would include all elements of the production process, including logistics, time management, financial planning, and other side processes. For example, the financial department in the virtual foundry would use data mining tools, which is the process of discovering new, meaningful correlations (interconnections) of patterns and trends by crawling large volumes of data stored in data storage (data warehouses) using statistical and mathematical methods and techniques [3]. With data mining tools, specific business data can be used to gather the information that leads, for example, to a costing formula for casting heat treatment. For distributed parallel data processing, a structure called an artificial neural network, within the field of artificial intelligence, is used.

"Neural networks are suitable for solving problems we don't know, we don't understand enough, and we are unable to describe them appropriately. Regulators or models that adapt to the network learning mechanism are also addressed as neural networks. The neural network can be used to learn by pattern (to track the interventions of an experienced operator in a variety of situations). In most situations, a learned (trained) network works well, but it does not help us understand the nature of the problem. Sometimes it fails unexpectedly in certain situations." [4].

Implementing a program for a neural network is not a very complicated problem. It is a sum-of-product and a not very complicated nonlinear function. Neural network can also be implemented by PLC or microcontroller. Much bigger problem is network learning, not only from the point of view of numerical difficulty of learning algorithm but also from the point of view of qualification and experience of the solver. Computing programs are often used, such as Matlab or Mathematica.

In 2006, the European Union launched the DiFac (Digital Factory for Human Oriented Production System) project, which sought to develop an innovative collaborative manufacturing environment (CME) for the next generation of digital manufacturing [5]. DiFac CME has been used as a framework to support the most important areas of the digital factory: group work (collaboration) in an interactive way, product prototyping, product design, and new employee training. This project has helped to create one of the first production collaborative environments, allowing users to systematically represent products and knowledge in 3D.

In earlier times, to increase foundry productivity and competitiveness, input prices had to be lowered while maintaining the same output while trying to reach the highest possible number of potential customers. However, only these factors are not sufficient today. Acquisition of new technologies and their deployment also play an important role. To deploy new technologies, foundries are increasingly inclined to use cloud computing, which will be described in the next chapter.

\subsection{Use of cloud computing tools in foundry industry}

Cloud computing can be defined as a new form of computer usage where data is processed, stored and managed on remote servers hosted on the Internet instead of a local server or personal computer. Cloud 
computing has become a major technology trend, and many experts assume that it will change not only information technology processes but also the entire IT market. Cloud computing can also be characterized as providing services or programs with servers available from the Internet, with users being able to access them remotely from their devices (including personal computers, laptops, smartphones, and PDAs), such as a web browser or e-mail client. If the service is paid, the user pays not for the software license but for its usage [6].

Many users use cloud services without being aware of it. The biggest providers of cloud solutions in the Czech Republic are Seznam.cz and Uloz.to. When it comes to e-mail service providers, user mailboxes are also in the cloud. The largest enterprise cloud providers include Microsoft (Azure), Amazon (Amazon Web Services), IBM, and Google. The revenue that companies achieve through the provision of cloud services is high and growing in nature. The revenue for Azure was USD 7.8 billion after one year of operation, and quarterly service revenues are up almost $25 \%$, having a very positive impact on Microsoft shares, which have skyrocketed from $\$ 72$ a share since August 2017 to the current $\$ 130$ a share. Basically, there is a dual division of cloud computing:

- $\quad$ how cloud services are provided (deployment model) and

- what the nature of the service that the cloud provides is (distribution model).

The deployment model describes how the cloud is provided and is divided into:

- Public cloud computing - Sometimes referred to as the classic cloud computing model. It is a scheme in which a computing service is offered to the general public and is characterized by the same or very similar functionality across all clients. Examples of public cloud computing include Skype and Seznam.cz.

- $\quad$ Private cloud computing - The cloud is run for the organization only, either by the organization itself or by a third party. An example of private cloud computing is e.g. a hosted mail server or a hosted dedicated application where typically 50 to 500 customers are on a single provider.

- Hybrid cloud computing-a hybrid cloud is a combination of a public and private cloud. On the outside, hybrid clouds act as one cloud, but they are linked using standardization technologies.

- Community cloud computing-a model where cloud infrastructure is shared among several organizations, a group of people using it. These organizations may associate security policy, the same field of interest, etc.

Layers of the distribution model show what is being offered in the service - whether it is software, hardware or a combination of them [7]:

- laaS-Infrastructure as a Service - The service provider is committed to providing infrastructure. Typically, this is virtualization. The main advantage of this approach is that the provider takes care of all hardware issues. laas is suitable for those who own software (or their licenses) and do not want to worry about hardware.

- $\quad$ PaaS-Platform as a Service - The provider guarantees complete resources to support the entire lifecycle of creating and delivering web applications and services, fully on the internet, without the possibility to download software. The concept includes various tools for developing applications such as IDEs or APIs, but also for maintenance. The disadvantage of this approach is the proprietary lockout, where different providers can use, for example, different programming languages. Well known PaaS provider is the Google App Engine.

- SaaS-Software as a Service - The application is licensed as a service rented by users. Therefore, users buy access to the app, not the app itself. SaaS is ideal for those who only need common application software and require access from anywhere, anytime. A good example is a set of applications called Google Apps, or in logistics, well-known Cargopass system. 
Foundry companies generate large quantities of data in each activity of the production process (e.g. in the heat treatment of castings). Thanks to the use of data mining tools this data can be used, for example, to create formulas for calculating the cost of gas consumption. The data must be stored safely somewhere with automatic backup options, which solves cloud computing. Foundries will therefore no longer have to deal with investing in large IT structures and servers. By virtualization, foundries can use programs for very complex calculations that take not hours but seconds or at most units of minutes. The possibilities are really wide and depend on the particular foundry as required.

In general, the use of virtual PCs is being promoted in the foundry industry, where, for example, several virtual PCs can run independently of each other on a single server, each of which manages some production or another aggregate (annealing furnace, conveyor belt, etc.). The advantage of virtualization is that a separate computer may do not have to be allocated for each process, which would have to undergo maintenance, license fees, consumption of energy, and the need to keep track of its lifetime and to renew it continuously. In practice, the company is usually driven by a local server, and there is a redundant image in the cloud, which makes it possible to recover the system in the event of its failure. In practice, you can see the opposite approach when the system is working in the cloud and its image is ready to be used on a local business server in the event of a failure.

It is also easier to back up data since most cloud service providers automatically back up all data (usually at least in two other locations that are geographically differentiated). Companies do not have to worry about data backups anymore, and if the user makes a local backup anyway, the probability of fatal data loss will be limited to zero [8].

\section{VIRTUAL FOUNDRY CONCEPT}

In this chapter, the idea design of a virtual foundry will be presented, divided into individual processes and sub-processes, of which the main casting processes will be described in more detail.

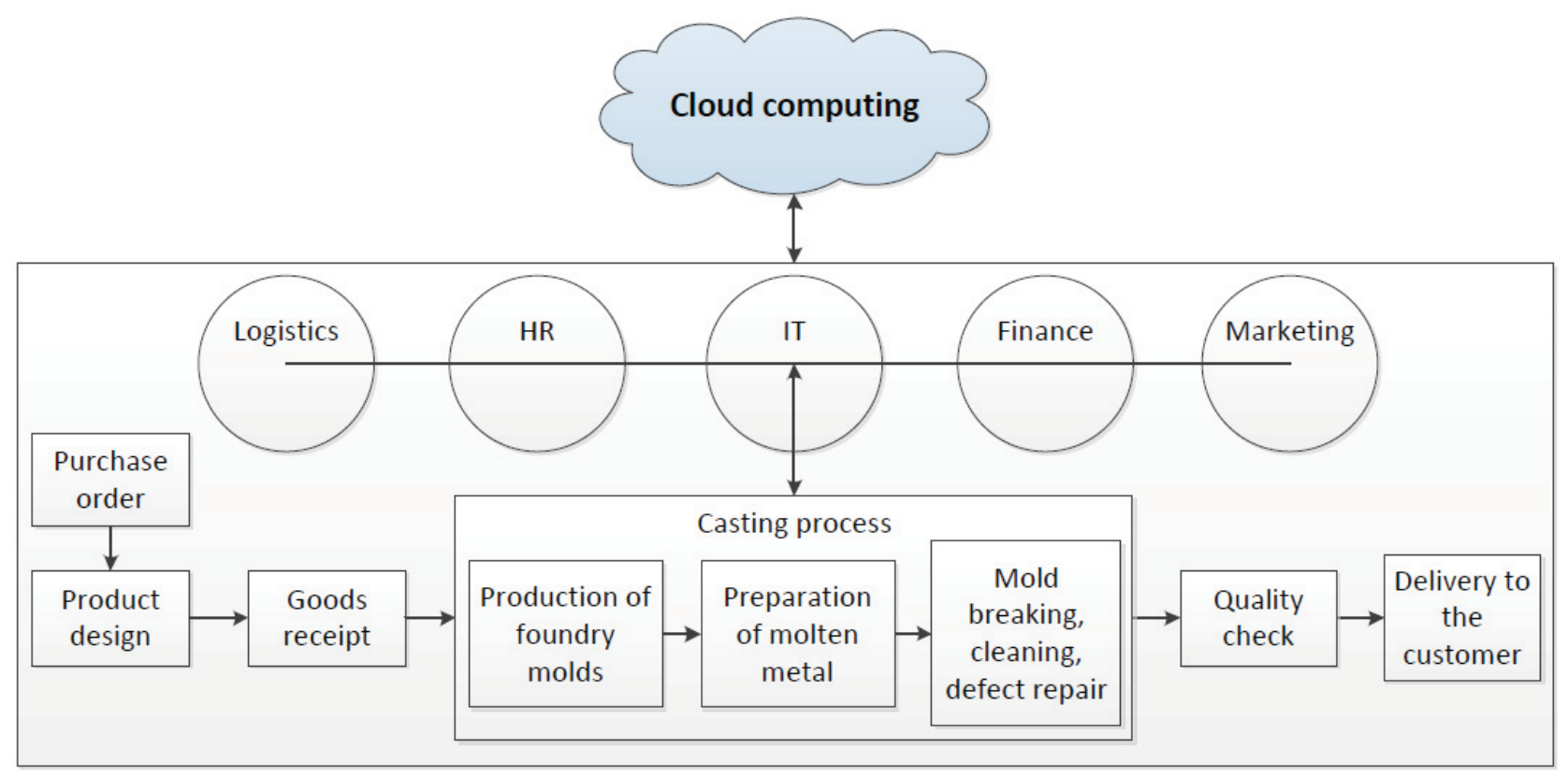

Figure 1 Design of virtual foundry using cloud computing

Figure 1 shows the design of a virtual foundry using cloud computing, which includes all processes of a real foundry company going in the following order: Order reception, product design, material receipt. This is 
followed by the main casting process, which includes the production of foundry molds, liquid metal preparation, casting, cleaning, and defect repair. Followed by quality control of castings and delivery of final products to the customer. All these processes are constantly pervading other processes, including logistics, human resources, information technology, finance, and marketing.

As mentioned in the previous chapters, virtual foundry will have very high hardware requirements. That is why the author of this article recommends operating the entire virtual foundry in the cloud. Recommended services include Microsoft Azure, Rackspace, Amazon Web Service, and Google Compute Engine. laaS (Infrastructure as a Service), then appears to be the most appropriate cloud distribution model for a virtual foundry.

\subsection{Production of foundry molds}

The aim is to create a cavity in the molding mixture whose edges correspond to the shape of the future casting. Molds are divided into non-permanent and permanent. Non-permanent molds are produced by molding from molding compounds. Non-permanent molds are produced manually or mechanically using models and core boxes. The molding compositions used to make non-permanent molds disintegrate after casting and removal from the mold and are reused after regeneration. Molding frames and molding equipment are used repeatedly. Non-permanent forms are disposable and account for about $95 \%$ of the molds used. Permanent molds are used multiple times (for example, up to 150,000x for zinc alloys). The basic materials for permanent molds are metal alloys (cast iron, alloy steel, but also special materials such as tungsten, molybdenum alloys, etc.). Molds are produced from blocks by chip machining, sometimes by powder metallurgy. The basic casting methods include gravity casting, die casting, centrifugal casting and continuous casting. The process of preparing the liquid metal follows.

\subsection{Preparation of molten metal}

The aim of the liquid metal preparation is to achieve its prescribed chemical composition and purity (minimum content of gases and impurities). The preparation of liquid metal is influenced by the quality of the charge materials, the type of melting furnace and the metallurgical process used (oxidation of the elements, alloying can influence the chemical composition, gas content, and impurities in the liquid metal). The melting and metallurgical processes in the furnace are followed by heating the molten metal to the tapping temperature, then pouring the molten metal out of the furnace into a ladle lined with a refractory lining. Liquid metal quality after melting can also be influenced by micro-alloying. After casting, the cast in the mold solidifies and cools (the appropriate setting and cooling rate are related to the type of casting material). The process of moldbreaking, cleaning and defect repair follows.

\subsection{Mold-breaking, cleaning, defect repair}

After cooling to the desired temperature, the mold is shaken off (the mold is broken). Vibration equipment, grinding grates or a hammer are used to break the castings. The molding mixture, together with the molding frames, returns to the production cycle. The casting is cleaned of the remnants of the molding mixture. Possible defects of castings are repaired by welding or by sealing. If the mechanical properties need to be improved and the casting structure removed, the castings are heat treated. Castings are checked for dimensional accuracy, surface quality, required structure, and mechanical properties and internal homogeneity. If the castings meet the properties prescribed by the acceptance conditions, they are ready for dispatch [9].

\section{CONCLUSION}

The author of this article would like to deal with virtualization in the foundry industry in the future. The longterm goal is to create a virtual foundry design, which is the application of the principle of digital factories to foundry enterprises. In the previous text, the theoretical basis of virtualization in foundry with the connection to modern cloud computing technologies was defined on the basis of available literary sources. In the 
application part of the article, individual processes included in virtual foundry were presented by using a simple diagram. The main casting processes have been described more specifically for better understanding. The author would like to elaborate his design in the future not only in the form of a dissertation but also in a complex hardware and software solution.

\section{ACKNOWLEDGEMENTS}

This article was supported by the specific university researches No. SP2019/17 and No. SP2019/62.

\section{REFERENCES}

[1] PORTNOY, Matthew. Virtualization Essentials. Indianapolis, Indiana: John Wiley \& Sons, Inc, 2012.

[2] REDAELLI, Claudia, Glyn LAWSON, Marco SACCO. DiFac: Digital Factory for Human Oriented Production System. Human-Computer Interaction [online]. 2009 [viewed 2019-04-09]. Available from: DOI:10.5772/7726.

[3] LAROSE, Daniel T. and Chantal D. LAROSE. Discovering Knowledge in Data: An Introduction to Data Mining. 2. ed. Hoboken, NJ: Wiley [u.a.], 2014.

[4] MAIXNER, Ladislav. Mechatronika: učebnice. Brno: Computer Press, 2006.

[5] Digital factory for human oriented Production System | Projects | FP6 | CORDIS | European Commission [online]. [viewed 2019-04-09]. Available from: https://cordis.europa.eu/project/rcn/79403/factsheet/en.

[6] FURHT, Borivoje and Armando ESCALANTE, ed. Handbook of Cloud Computing. New York: Springer, 2010.

[7] LYNLEY, Matthew. Microsoft's Azure revenue nearly doubled year-over-year in its second quarter. TechCrunch [online]. 31. january 2018 [viewed 2018-06-02]. Available from: http://social.techcrunch.com/2018/01/31/microsofts-azure-revenue-nearly-doubled-year-over-year-in-itssecond-quarter/.

[8] FRIDRICH, Michal, Tomáš TYKVA, Ivo ŠPIČKA a Lucie TREUTLEROVÁ. Cloud computing a Průmysl 4.0. Slévárenství. 2018, vol. 7-8. pp. 272-276.

[9] ČADA, Radek. Technologie tváření a slévání - teoretický základ. Ostrava: VŠB-TU Ostrava, 2013. 